\title{
Role of First Trimester Sex Hormone-Binding Globuline and High-Sensitivity C-Reactive Protein in Predicting Gestational Diabetes Mellitus
}

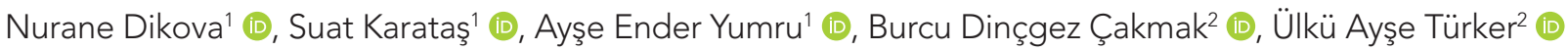 \\ 1Department of Gynecology and Obstetrics, University of Health Sciences Şişli Hamidiye Etfal Training and Research Hospital, i̇stanbul, Turkey \\ 2Department of Gynecology and Obstetrics, University of Health Sciences Bursa Yüksek Ihtisas Training and Research Hospital, Bursa, Turkey
}

Cite this article as: Dikova N, Karataş S, Ender Yumru A, Dinçgez Çakmak B, Türker ÜA. Role of First Trimester Sex Hormone-Binding Globuline and High-Sensitivity C-Reactive Protein in Predicting Gestational Diabetes Mellitus. JAREM 2019; 9(3): 130-4.

\begin{abstract}
Objective: We aimed to evaluate the role of sex hormone-binding protein and high-sensitivity C-reactive protein for predicting gestational diabetes mellitus.

Methods: A total of 99 pregnant women between $6^{\text {th }}$ and $14^{\text {th }}$ gestational weeks who were admitted to our obstetrics and gynecology outpatient clinic between February 2017 and July 2017 were included. Age, gestational week, last menstrual date, gravida, parity, height, weight, history of gestational diabetes mellitus, macrosomia and polyhydramnios, tobacco use, delivery mode, delivery weight, sex hormone-binding protein, and high-sensitivity C-reactive protein levels were recorded.

Results: No difference between gestational diabetes and control group with regard to age, gravida, parity, gestational age at delivery and tobacco use $(p>0.05)$ was noted. Body mass index, history of gestational diabetes, macrosomia and polyhydramnios, birth weight and cesarean rates were significantly higher in gestational diabetes group. Sex hormone-binding protein levels were $213.4 \pm 111.33 \mathrm{nmol} / \mathrm{L}$ in gestational diabetes and $251.64 \pm 137.94 \mathrm{nmol} / \mathrm{L}$ in control group, which were not significatly different between two groups $(p=0.325)$. High-sensitivity $\mathrm{C}$-reactive protein levels were $10.12 \pm 11.36 \mathrm{mg} / \mathrm{L}$ in gestational diabetes and $5.18 \pm 5.91 \mathrm{mg} / \mathrm{L}$ in control group and statistically significant difference was noted between two groups $(p=0.004)$. High-sensitivity $\mathrm{C}$-reactive protein $>3.25 \mathrm{mg} / \mathrm{L}$ was found to be a predictor for gestational diabetes with a sensitivity of $78 \%$ and specifity of $62 \%$.

Conclusion: First trimester high-sensitivity C-reactive protein was found to be a predictor for gestational diabetes mellitus in which early diagnosis has a critical role for reducing maternal and fetal mortality and morbidity.

Keywords: Gestational diabetes mellitus, sex hormone binding protein, high-sensitivity C-reactive protein
\end{abstract}

\section{INTRODUCTION}

Gestational diabetes mellitus (GDM) is defined as glucose intolerance of various degrees that developed during pregnancy or diagnosed in pregnancy for the first time and is the most common complication of pregnancy (1). It is known that $6 \%-7 \%$ of all pregnancies are complicated with diabetes, and approximately $90 \%$ of these pregnancies are diagnosed with $\operatorname{GDM}(2,3)$. The frequency of GDM varies according to the prevalence of type 2 diabetes, average age, screening-diagnostic criteria, and ethnicity of that population. GDM is more common in Spanish, American, Asian, and Icelandic populations (1). In America, the rate of GDM is reported to be $6 \%-7 \%$ (4). The prevalence of GDM, in the limited number of studies made in different cities in Turkey, var- ies between $3 \%$ and $9 \%$, and it is reported that this percentage increases to $11.4 \%$ depending on the diagnostic criteria $(5,6)$.

Maternal age, obesity, history of GDM or macrosomic infant birth in previous pregnancy, presence of GDM in first-degree relatives, history of abnormal glucose tolerance and being a member of an ethnic group at risk of type $2 \mathrm{DM}$, previous unexplained perinatal pregnancy loss or having a baby with anomaly, detection of glucosuria at the first prenatal visit, presence of polycystic ovary syndrome, use of glucocorticoids, and presence of essential hypertension or gestational hypertension are the main risk factors for $\operatorname{GDM}(7,8)$.

It has been shown that approximately $50 \%$ of women who develop diabetes during pregnancy would develop diabetes within

ORCID IDs of the authors: N.D. 0000-0003-1681-9232; S.K. 0000-0003-1592-0304; A.E.Y. 0000-0001-6449-1839; B.D.Ç. 0000-0002-2697-7501; Ü.A.T. 00000002-3393-6310. 
22-28 years of gestation (9). In addition, in pregnancies complicated with GDM, preeclampsia; polyhydramnios; preterm delivery; sudden fetal loss; birth trauma; cesarean rate; after delivery hypoglycemia, hypocalcemia, hyperbilirubinemia, and hyperviscosity; respiratory distress syndrome; sudden infant death; at later ages obesity; type 2 DM; cardiovascular disorders; and neurological intellectual problems have been shown to increase (9-12). The lack of good glycemic control is regarded to be responsible for the development of complications seen in gestational diabetes. Perinatal morbidity is proportional to the level of glycemic control of the mother (13). Therefore, early diagnosis, appropriate treatment, and follow-up of patients with GDM by screening during pregnancy are critical in preventing mortality and morbidity in the mother and baby due to diabetes (14).

The American College of Obstetricians and Gynecologists and the American Diabetes Association recommend screening for all pregnant women at 24-28 weeks of gestation with single- or double-step oral glucose tolerance test (OGTT) with respect to gestational diabetes $(15,16)$.

Although many factors have been proposed in the etiopathogenesis of gestational diabetes, this issue is still controversial. Previous studies have shown that inflammation plays an important role in the pathogenesis of GDM. Inflammatory molecules, such as tumor necrosis factor-alpha and C-reactive protein (CRP), are known to increase in GDM. CRP is associated with insulin resistance, hyperglycemia, and glucose intolerance. In addition, the relationship of high-sensitivity CRP (hsCRP) with obesity and diabetes mellitus is proven (17). hsCRP is a prototype acute phase protein from the "pentraxin" family consisting of non-covalently linked five identical subunits weighing $120 \mathrm{kDa}$ (18). It is produced after tissue damage, inflammation, and infection (17). Another effective marker in glucose balance is sex hormone-binding globulin (SHBG). Low levels of SHBG are frequently seen in cases of insulin resistance and are considered as a potential predictor of GDM and subsequent type $2 \mathrm{DM}$ in overweight populations $(19,20)$. The prospective cross-sectional study evaluating serum SHBG levels reported that SHBG concentrations were significantly lower in patients with GDM than in normal pregnancies $(21,22)$.

The practical feasibility of the proposed OGTT in GDM screening is becoming increasingly difficult. Beliefs in Turkish society, false reports on social media, and drinking of glucose water that triggers digestive system disorders during pregnancy are the main challenges. In the present study, the levels and the role in predicting GDM of SHBG and hsCRP, which can be an alternative to OGTT performed at 24-28 weeks of gestation and provide the diagnosis of GDM in early gestational weeks, were examined in patients with GDM in a Turkish population.

\section{METHODS}

The study was performed with 100 pregnant women at 6-14 weeks of gestation who were admitted to the obstetrics clinic for routine antenatal follow-up between February 2017 and July 2017. Inclusion criteria were women age 18-40 years, singleton pregnancy at 6-14 weeks of gestation, first trimester hemoglobin A1c $<6 \%$, fasting plasma glucose (FPG) $<126 \mathrm{mg} / \mathrm{dL}$, and postprandial plasma glucose $(\mathrm{PPG})<200 \mathrm{mg} / \mathrm{dL}$. Exclusion criteria were presence of a diagnosis of type 1 or type $2 \mathrm{DM}$, presence of any endocrinopathy or inflammatory disease, using a drug effective on carbohydrate metabolism, having multiple pregnancies, and failure to provide verbal or written consent to the study. One pregnant woman was excluded from the study because of abortion at 18 weeks of gestation. A total of 99 patients were included in the study.

The gestational weeks of the pregnant women included in the study were determined by their last menstrual period and ultrasonography examination. Age; gestational age; last menstrual period; gravida; parity; weight; length; history of GDM, macrosomia, and polyhydramnios; smoking; mode of delivery; and birth weight were recorded. Blood samples were also obtained for hsCRP and SHBG after $8 \mathrm{~h}$ of fasting with their routine examination. In addition, $75 \mathrm{~g}$ of OGTT was performed between 24 and 28 weeks of gestation for the screening of GDM. No diet program was applied to pregnant women before this procedure. Normal values were based on the levels recommended by the International Diabetes and Pregnancy Study Group. Considering the FPG $\leq 92 \mathrm{mg} / \mathrm{dL}$, $1 \mathrm{st}$ hour $\leq 180 \mathrm{mg} / \mathrm{dL}$, and $2 \mathrm{nd}$ hour $\leq 153 \mathrm{mg} / \mathrm{dL}$ as normal limits, 14 of the 99 pregnant women were diagnosed with GDM. Pregnant women with GDM were referred to the endocrinology outpatient clinic for treatment planning. At first, diet therapy was started to all patients. The patients were asked to note fasting and postprandial blood glucose levels for 2 weeks. At the end of 2 weeks, insulin therapy was started in four pregnant women with an FPG $\geq 105 \mathrm{mg} /$ $\mathrm{dL}$ or a PPG at $1 \mathrm{~h} \geq 140 \mathrm{mg} / \mathrm{dL}$.

The study was approved by the Clinical Research Ethics Committee of Şişli Hamidiye Etfal Training and Research Hospital (decision no. 747, 02/21/2016). Written consent was obtained from all participants.

\section{Statistical Analysis}

Data were analyzed by the Statistical Package for Social Sciences version 20.0 (IBM Corp., Armonk, NY, USA) program. Shapiro-Wilk test was used to determine the normal distribution of variables. Descriptive data were expressed as mean \pm standard deviation, percentage, and median (minimum:maximum). For comparisons between the patient and control groups, Student's t-test was used for normally distributed variables, Mann-Whitney $U$ test was used for variables with non-normal distribution, and chi-square test was used for categorical variables. The receiver operating characteristic ( $\mathrm{ROC}$ ) analysis was performed to evaluate the predictive power of SHBG and hsCRP for GDM, and the sensitivity, specificity, and positive and negative predictive values were calculated. A $p$ value of $<0.05$ was considered to be statistically significant for all analyses.

\section{RESULTS}

The mean age of all patients included in the study was $27.79 \pm 5.54$ (minimum 18: maximum 43) years. The mean gravida was 2 (1:4), and the mean parity was 1 (1:3). Of the 99 patients, 14 (14.1\%) were smokers, 7 (7.1\%) had a history of GDM, 3 (3\%) had macrosomia, and 5 (5.1\%) developed polyhydramnios during the current pregnancy. Cesarean section rate was calculated as $23 \%$.

The features of the GDM and control groups are shown in Table 1. There was no significant difference between the two groups 
with respect to age, gravida, parity, gestational week at birth, and smoking ( $p>0.05)$. Body mass index (BMI), history of GDM in previous pregnancy, macrosomia development during the current pregnancy, polyhydramnios development, birth weight, and cesarean delivery rate were significantly higher in the GDM group than in the control group. The levels of SHBG were 213.4 \pm 111.33 $\mathrm{nmol} / \mathrm{L}$ in the GDM group and $251.64 \pm 137.94 \mathrm{nmol} / \mathrm{L}$ in the control group, and no significant difference was found between the two groups $(p=0.325)$. The levels of hsCRP were $10.12 \pm 11.36 \mathrm{mg} / \mathrm{L}$ in the GDM group and $5.18 \pm 5.91 \mathrm{mg} / \mathrm{L}$ in the control group, and there was a statistically significant difference between the two groups $(p=0.004)$.

When the ROC curve was drawn to evaluate the role of hsCRP in predicting GDM, the area under the curve was 0.72 , and the cut-off value was $3.25 \mathrm{mg} / \mathrm{L}(p=0.007)$. In the diagnosis of GDM, the sensitivity of hsCRP was $78 \%$, and the specificity was $62 \%$. Positive and negative predictive values were calculated as $67.2 \%$ and $73.8 \%$, respectively. The ROC curve showing the value of the hsCRP parameter in the GDM diagnosis is shown in Figure 1.

\section{DISCUSSION}

GDM, which is defined as glucose intolerance that developed during pregnancy or diagnosed during pregnancy, is a condition that can be accompanied with diabetes, hypertension, and cardiovascular and neurological complications in the future maternal and infant life cycle (1). Studies have shown that the earlier the diagnosis and treatment of patients with GDM, less complications can occur. Nanda et al. (23), in their study on the early detection of complications that may occur during pregnancy, showed that advanced maternal age, increased BMI, ethnicity, history of GDM in previous pregnancies, and history of delivery of macrosomic infant may be a determinant for the development of GDM in subsequent pregnancies. In our study, BMI, history of GDM in previous pregnancy, development of macrosomia during the current pregnancy, development of polyhydramnios, birth weight, and cesarean delivery rate were significantly higher in the GDM group than in the control group.

Inflammation is known to play a role in the pathogenesis of GDM. Therefore, many inflammatory molecules have been investigated in the diagnosis and prognosis of GDM. One of

Table 1. Characteristics of the GDM and control groups

\begin{tabular}{|c|c|c|c|}
\hline & GDM & Control & $p$ \\
\hline Age (year) & $29.57 \pm 4.65$ & $27.49 \pm 5.63$ & 0.096 \\
\hline $\mathrm{BMI}\left(\mathrm{kg} / \mathrm{m}^{2}\right)$ & $30.18 \pm 5.44$ & $23.72 \pm 2.37$ & $<0.001$ \\
\hline Gravida & $3(1: 4)$ & $2(1: 3)$ & 0.142 \\
\hline Parity & $2(1: 3)$ & $1(1: 3)$ & 0.142 \\
\hline \multicolumn{4}{|l|}{ Smoking } \\
\hline -Yes & $2(14.3 \%)$ & $12(14.1 \%)$ & 0.987 \\
\hline$-\mathrm{No}$ & $12(85.7 \%)$ & $73(85.1 \%)$ & \\
\hline \multicolumn{4}{|l|}{ History of GDM } \\
\hline -Yes & $7(50 \%)$ & $0(0 \%)$ & $<0.001$ \\
\hline$-\mathrm{No}$ & $7(50 \%)$ & $85(100 \%)$ & \\
\hline \multicolumn{4}{|l|}{ Macrosomia } \\
\hline -Yes & $3(21.4 \%)$ & $0(0 \%)$ & $<0.001$ \\
\hline$-\mathrm{No}$ & $11(78.6 \%)$ & $85(100 \%)$ & \\
\hline \multicolumn{4}{|l|}{ Polyhydramnios } \\
\hline -Yes & $5(35.7 \%)$ & $0(0 \%)$ & $<0.001$ \\
\hline$-\mathrm{No}$ & $9(64.3 \%)$ & $85(100 \%)$ & \\
\hline Gestational week at delivery & $38.71 \pm 0.72$ & $39.31 \pm 1.25$ & 0.062 \\
\hline \multicolumn{4}{|l|}{ Mode of delivery $(n, \%)$} \\
\hline -Normal & $10(71.4 \%)$ & $67(78.8 \%)$ & 0.023 \\
\hline -Cesarean & 4 (28.6\%) & $18(21.2 \%)$ & \\
\hline Birth weight (g) & $3767.86 \pm 260.12$ & $3365.41 \pm 225.55$ & $<0.001$ \\
\hline Level of SHBG (nmol/L) & $213.4 \pm 111.33$ & $251.64 \pm 137.94$ & 0.325 \\
\hline Level of hsCRP (mg/L) & $10.12 \pm 11.36$ & $5.18 \pm 5.91$ & 0.004 \\
\hline
\end{tabular}




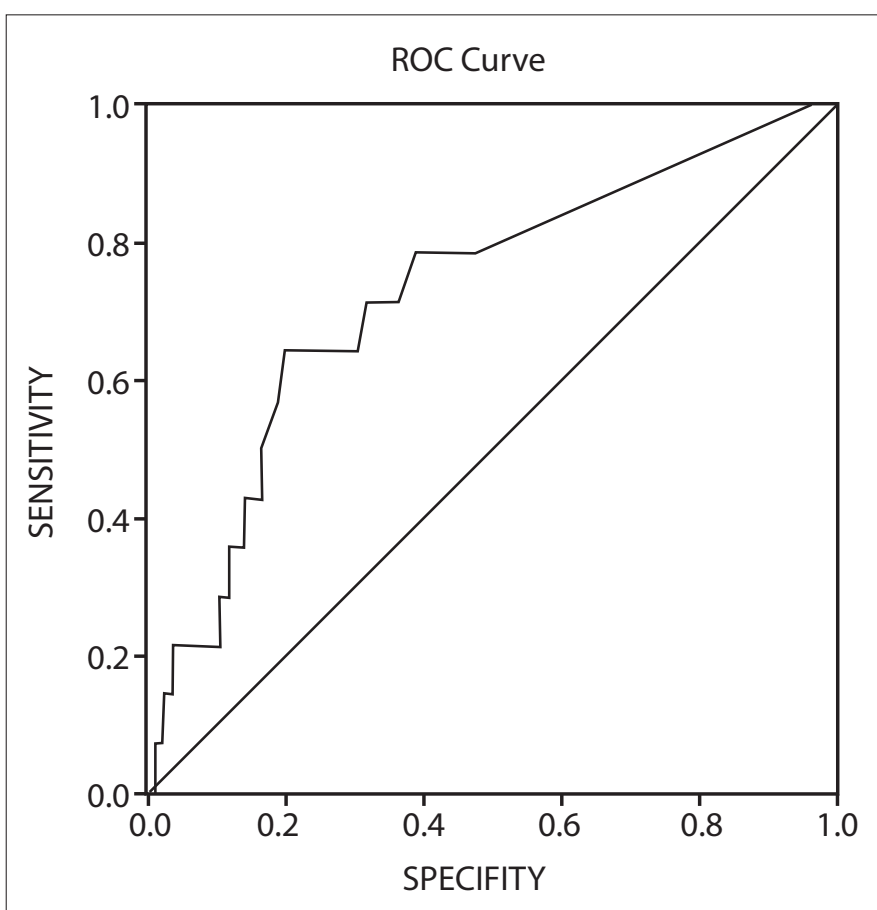

Figure 1. The role of hsCRP in predicting gestational diabetes mellitus

these molecules is hsCRP. Denisson et al. (24) hypothesized that maternal obesity, which is known to be a risk factor for GDM, produces a low-grade inflammatory state. Therefore, hsCRP is considered to be a risk factor for any obesity-related disease, such as metabolic and cardiovascular diseases. Therefore, the hypothesis that hsCRP, an inflammatory molecule, may be also high in GDM has been established and supported by studies $(25,26)$. Bo et al. (27), in their study in 2005 , showed that hsCRP increases as if to promote the inflammatory process in GDM, and that this is associated with BMI. Wolf et al. (28), in a case control study in 2003, evaluated CRP levels in the first trimester in 43 patients with GDM and 94 normoglycemic patients and found that the CRP levels of the first 3 months are significantly higher in the GDM group than in the control group. In our study, hsCRP was also found to be higher in the GDM group than in the control group. In addition, in our study, it was determined that hsCRP values $>3.25 \mathrm{mg} / \mathrm{L}$ predicted GDM with $78 \%$ sensitivity and $62 \%$ specificity.

Sex hormone-binding globulin (SHBG). is another molecule that has been shown to be associated with insulin resistance and the development of type 2 DM. Low levels of SHBG (regardless of gender) was found to be determinative for type $2 \mathrm{DM}(29,30)$. Owing to the inhibitory effect of both insulin and insulin-like growth factor 1 on SHBG secretion by HepG2 cells in vitro, SHBG levels are thought to be an indicator of insulin resistance or hyperinsulinemia (31). Çağlar et al. (32) evaluated the predictive value of SHBG in GDM in a study with 93 pregnant women and found that 30 pregnant women have complications with GDM, and that the SHBG values of these women at 13-16 weeks are lower than those of the control group. In the same study, they also concluded that SHBG, for the prediction of GDM, is valuable in screening early pregnancy.
In another study evaluating the relationship between SHBG and GDM, it was determined that the possibility of GDM development increased in patients with low SHBG levels in the first trimester, and that the decrease in SHBG levels was more prominent in patients who were in need of insulin use (31). In the study by Maget et al. on the role of SHBG in predicting GDM, it was shown that SHBG predicts GDM with $85 \%$ sensitivity and $37 \%$ specificity. Another highlight in this study is that hsCRP and SHBG were combined to evaluate their roles in predicting GDM. It was found that the combination of hsCRP and SHBG showed GDM with $75.46 \%$ accuracy (33). SHBG is affected by genetic heterogeneity in addition to hormonal and metabolic factors, and recent findings suggest that inherited single nucleotide polymorphisms in the SHBG gene carry the risk of developing GDM and type 2 DM. SHBG levels are inversely proportional to insulin concentrations and insulin resistance $(19,20)$. In our study, SHBG levels were not significant in GDM. We think that the reason for this may be the genetic polymorphism in Turkish society or the small number of patients in our study.

\section{Limitations of the Study}

Our study has several limitations. First, it is a single-center study. Second, it has a small number of patients. Moreover, the fact that the evaluated markers were not repeated in the second trimester may be considered as another limitation.

\section{CONCLUSION}

GDM is the most common complication of pregnancy. It is a condition where mortality and morbidity can be significantly reduced in both maternal and fetal terms with early diagnosis. Therefore, the prediction of GDM in the early weeks of pregnancy by biochemical markers is very important. In conclusion, hsCRP in the first trimester may be predictive for GDM.

Ethics Committee Approval: Ethics committee approval was received for this study from the Ethics Committee of Clinical Research of University of Health Sciences Şişli Hamidiye Etfal Training and Research Hospital (21.02.2016/747).

Informed Consent: Written informed consent was obtained from patients who participated in this study.

Peer-review: Externally peer-reviewed.

Author Contributions: Concept - A.E.Y.; Design - N.D.; Supervision A.E.Y.; Resources - N.D., S.K.; Data Collection and/or Processing - N.D., S.K.; Analysis and/or Interpretation - B.D.Ç., Ü.A.T.; Literature Search Ü.A.T.; Writing Manuscript - B.D.Ç., A.E.Y.; Critical Review - A.E.Y., B.D.Ç.

Conflict of Interest: The authors have no conflict of interest to declare.

Financial Disclosure: The authors declared that this study has received no financial support.

\section{REFERENCES}

1. Mark B, Landon MD, Wanda K, Nicholsan MD. The American college of Obstetricans and Gestational Diabetes Mellitus. ACOG Practice Bulletin 2013: 406-16.

2. Marquette GP, Klein VR, Niebyl JR. Efficacy of screening for gestational diabetes. Am J Perinatol 1985; 2: 7-9. [CrossRef]

3. Wier LM, Witt E, Burgess J, Elixhauser A. Hospitalizations related to Diabetes in Pregnancy, 2008. HCUP Statistical Brief 102. Rockville (MD): Agency for Healthcare Research and Quality; 2010. Retrieved April 24, 2012.

4. Wier LM, Witt E, Burgess J, Elixhauser A. Diagnosing gestational diabetes mellitus. National Institutes of Health Consensus Deve- 
lopment Conference Statement. NIH Consens State Sci Statements 2013; 29: 1-30.

5. Özçimen EE, Uçkuyu A, Çiftçi FC, Yanık FF, Bakar C. Diagnosis of gestational diabetes mellitus by use of the homeostasis model assessment insülin resistance index in the first trimester. Gynecol Endocrinol 2008; 24: 224-9. [CrossRef]

6. Gürel C, Özgün MT, Batukan C, Bağbuğ M. Prevalence of gestational diabetes among pregnant women attending Erciyes University Medical Faculty. Erciyes Med J 2009; 31: 323-30.

7. Solomon CG, Willett WC, Carey VJ, Rich-Edwards J, Hunter DJ, Colditz GA, et al. A prospective study of pregravid determinants of gestational diabetes mellitus. JAMA 1997; 278: 1078-83. [CrossRef]

8. Karcaaltincaba D, Kandemir O, Yalvac S, Güvendag-Guven S, Haberal A. Prevalence of gestational diabetes mellitus and gestational impaired glucose tolerance in pregnant women evaluated by National Diabetes Data Group and Carpenter and Coustan criteria. Int J Gynecol Obstet 2009; 106: 246-9. [CrossRef]

9. England LJ, Dietz PM, Njoroge T, Callaghan WM, Bruce C, Buus RM, et al. Preventing type 2 diabetes: public health implications for women with a history of gestational diabetes mellitus. Am J Obstet Gynecol 2009; 200: 365.e1-8. [CrossRef]

10. HAPO Study Cooperative Research Group. Hyperglycemia and adverse pregnancy outcomes. N Engl J Med 2008; 358: 1991-2002. [CrossRef]

11. Burumkulova FF, Petrukhin VA. Gestational diabetes mellitus: yesterday, today, tomorrow. Ter Arkh 2014; 86: 109-15.

12. Cedergren MI. Optimal gestational weight gain for body mass index categories. Obstet Gynecol 2007; 110: 743-4. [CrossRef]

13. Crowther CA, Hiller JE, Moss JR, McPhee JE, Jeffries WS, Robinson JS. Effect of Treatment of Gestational Diabetes Mellitus on Pregnancy Outcomes. N Engl J Med 2005; 352: 2477-86. [CrossRef]

14. Kiel DW, Dodson EA, Artal R, Boehmer TK, Leet TL. Gestational weight gain and pregnancy outcomes in obese women: how much is enough? Obstet Gynecol 2007; 110: 752-8. [CrossRef]

15. ACOG Practice Bulletin. Clinical management guidelines for obstetrician-gynecologists. Obstet Gynecol 2001; 98: 525-38.

16. Tseng KH. Standards of medical care in diabetes--2006: response to the American Diabetes Association. Diabetes Care 2006; 29: 2563-4. [CrossRef]

17. Qiu C, Sorensen TK, Luthy DA, Williams MA. A prospective study of maternal serum $C$ reactive protein (CRP) concentrations and risk of gestational diabetes mellitus. Paediatr Perinat Epidemiol 2004; 18 : 377-84. [CrossRef]

18. Pepys MB. C-reactive protein fifty years on. Lancet 1981; 1: 653-7. [CrossRef]

19. Pugeat M, Crave JC, Tourniaire J, Forest MG. Clinical utility of sex hormone-binding globulin measurement. Horm Res 1996; 45: $148-$ 55. [CrossRef]
20. Hu J, Zhang A, Yang S, Wang Y, Goswami R, Zhou H, et al. Combined effects of sex hormone-binding globulin and sex hormones on risk of incident type 2 diabetes. J Diabetes 2016; 8: 508-15. [CrossRef]

21. Bartha JL, Comino-Delgado R, Romero-Carmona R, Gomez-Jaen MC. Sex hormone binding globulin in gestational diabetes. Acta Obstet Gynecol Scand 2000; 79: 839-45. [CrossRef]

22. Festa A, Krugluger W, Schernthaner G. Low levels of sex-hormonebinding globulin predict insulin requirement in patients with gestational diabetes mellitus. Exp Clin Endocrinol Diabetes 2001; 109: 365-9. [CrossRef]

23. Nanda S, Savvidou M, Syngelaki A, Akolekar R, Nicolaides KH. Prediction of gestational diabetes mellitus by maternal factors and biomarkers at 11 to 13 weeks. Prenat Diagn 2011; 31: 135-41. [CrossRef]

24. Denison FC, Roberts KA, Barr SM, Norman JE. Obesity, pregnancy, inflammation, and vascular function. Reproduction 2010; 140: 37385. [CrossRef]

25. Festa A, D'Agostino R, Howard G, Mykkänen L, Tracy RP, Haffner $\mathrm{SM}$. Chronic inflammation as part of the insulin resistance syndrome: the Insulin Resistance Atherosclerosis Study (IRAS). Circulation 2000; 102: 42-7. [CrossRef]

26. Kelly CC, Lyall H, Petrie JR, Gould GW, Connell JM, Sattar N. Low grade chronic inflammation in women with polycystic ovarian syndrome. J Clin Endocrinol Metab 2001; 86: 2453-5. [CrossRef]

27. Bo S, Signorile A, Menato G, Gambino R, Bardelli C, Gallo ML. $\mathrm{C}$-reactive protein and tumor necrosis factor-alpha in gestational hyperglycemia. J Endocrinol Invest 2005; 28: 779-86. [CrossRef]

28. Wolf M, Sandler L, Hsu K, Vossen-Smirnakis K, Ecker JL, Thadhani R. First-trimester $\mathrm{C}$-reactive protein and subsequent gestational diabetes. Diabetes Care 2003; 26: 819-24. [CrossRef]

29. Ding EL, Song Y, Manson JE, Hunter DJ, Lee CC, Rifai N. Sex hormone-binding globulin and risk of type 2 diabetes in women and men. N Engl J Med 2009; 361: 1152-63. [CrossRef]

30. Haffner SM, Valdez RA, Morales PA, Hazuda HP, Stern MP. Decreased sex hormone binding globulin predicts noninsulin dependent diabetes mellitus in women but not in men. J Clin Endocrinol Metab 1993; 77: 56-60. [CrossRef]

31. Pugeat M, Crave JC, Touniaire J, Forest MG. Clinical utility of sex hormone-binding globulin measurement. Horm Res 1996; 45: 14855. [CrossRef]

32. Caglar GS, Ozdemir ED, Cengiz SD, Demirtas S. Sex-hormone binding globulin early in pregnancy for the prediction of severe gestational diabetes mellitus and related complications. J Obstet Gynecol Res 2012; 38: 1286-93. [CrossRef]

33. Maged AM, Moety GAF, Mostafa WA, Hamed DA. Comparative study between different biomarkers for early prediction of gestational diabetes mellitus. Maternal Fetal Neonatal Med 2014: 27: 110812. [CrossRef] 